\title{
Prevalence of COVID-19 Infection in Patients with Neuromyelitis Optica Spectrum Disorder
}

\author{
Abdorreza Naser Moghadasi (iD) ${ }^{1}$, Aida Mohammadi ${ }^{1}$, Mohammad Ali Sahraian ${ }^{1}$ and Mahsa \\ Ghajarzadeh ${ }^{1, *}$ \\ ${ }^{1}$ Multiple Sclerosis Research Center, Neuroscience Institute, Tehran University of Medical Sciences, Tehran, Iran \\ "Corresponding author: : Multiple Sclerosis Research Center, Neuroscience Institute, Tehran University of Medical Sciences, Tehran, Iran. Email: m.ghajarzadeh@gmail.com
}

Received 2021 August 07; Revised 2021 October 25; Accepted 2021 November 06.

Keywords: COVID-19, Coronavirus, Neuromyelitis Optica

\section{Dear editor,}

The novel coronavirus disease 2019 (COVID-19) is in the pandemic stage, and there are concerns about patients with autoimmune diseases $(1,2)$. Neuromyelitis optica spectrum disorder (NMOSD) is an autoimmune disease of the central nervous system (CNS), which predisposes cases to increased risk of infection based on immunosuppressive treatments (3). Up to now, NMOSD cases have been evaluated regarding COVID-19 infection, and different infection rates have been reported.

Thus, the aim of this systematic review and metaanalysis was to estimate the pooled prevalence of COVID-19 infection in patients with NMOSD.

Two independent researchers searched PubMed, Scopus, EMBASE, Web of Science, and google scholar and also gray literature up to October 20, 2020.

The search syntax for searching in PubMed was (coronavirus OR Wuhan coronavirus OR novel coronavirus OR coronavirus disease OR COVID-19 OR 2019 novel coronavirus infection OR 2019-nCOV OR severe acute respiratory syndrome coronavirus 2 OR SARS-CoV-2) AND Neuromyelitis optica spectrum disorder OR NMOSD OR Devic syndrome OR Neuromyelitis optica spectrum disorders.

STATA (Version 13.0; Stata Corp LP, College Station, TX, USA) was used for data analysis. Inconsistency $\left(\mathrm{I}^{2}\right)$ was calculated for heterogeneity evaluation.

We found 54 articles; however, after careful evaluation, five manuscripts were included for meta-analysis. Totally, 3458 patients with NMOSD had been evaluated (Table 1).

The pooled estimate of COVID-19 infection in NMOSD patients was $2 \%$ (95\% CI: $0-7 \%)\left(\mathrm{I}^{2}=80.6 \%, \mathrm{P}<0.001\right.$ ) (Figure 1).

Patients with NMOSD are prone to a wide range of infections based on immunosuppressive treatments and concerns raised during the COVID-19 pandemic. The incidence of COVID-19 in the general population ranges from 0.35 to $13.3 \%$ (8), while in NMOSD patients, the prevalence ranges from $0-12 \%$, and most cases had mild infection without the need for hospitalization (only seven out of 3458 hospitalized cases) or ICU admission (only one) as it is shown in Table1. The results also showed that no death was reported among NMOSD patients. This could be based on great care of these patients and also following preventive strategies and strict quarantine rules (3). Previous findings have shown that $\mathrm{B}$ cell depleting agents do not increase the risk of infection in NMOSD patients $(3,7)$.

A limited number of the included studies is the limitation of this study. The prevalence of COVID-19 infection is rare in NMOSD patients.

\section{Footnotes}

Authors' Contribution: AMN: Study conception, data gathering, article writing.; AM: Data gathering and article writing.; MAS: Data gathering and article writing.; MG: Study design, data analysis, article writing, and editing.

Conflict of Interests: The authors had no conflicts of interest.

Data Reproducibility: The datasets used and/or analyzed during the current study are not available from the corresponding author on reasonable request.

Ethical Approval: All methods were carried out in accordance with relevant guidelines and regulations. All experimental protocols were approved by the local ethics committee. 


\begin{tabular}{|c|c|c|c|c|c|c|c|c|c|c|}
\hline Number & Author & No. of Patients & Mean Age & $\mathbf{F} / \mathbf{M}$ & $\begin{array}{l}\text { Mean Disease } \\
\text { Duration }\end{array}$ & $\begin{array}{l}\text { The Most Common } \\
\text { Symptoms }\end{array}$ & $\begin{array}{l}\text { No. of Patients With } \\
\text { covD-19 }\end{array}$ & $\begin{array}{l}\text { No. of Hospitalized } \\
\text { Patients }\end{array}$ & ICUAdmission & Death \\
\hline 1 & Sinéad Zeidan (4) & 75 & 43.9 & 3.68 & 6 & $\begin{array}{l}\text { Fever, cough, } \\
\text { asthenia, haadache, } \\
\text { diarrhea, } \\
\text { ageusialanosmia, } \\
\text { asthenia, and } \\
\text { headache }\end{array}$ & 5 & 1 & 0 & 0 \\
\hline 2 & $\begin{array}{l}\text { Omid Mirmosayyeb } \\
\text { (3) }\end{array}$ & 157 & $38 \pm 10.8$ & 0.256 & $6 \pm 4$ & $\begin{array}{l}\text { myalgia, and } \\
\text { headache/vertigo }\end{array}$ & 8 & 3 & 1 & 0 \\
\hline 3 & Anna Tomczaka (5) & 17 & . & 4.6 & . & $\begin{array}{c}\text { Respiratory } \\
\text { Symmtoms, including } \\
\text { fever, chills, and } \\
\text { shortness of breath }\end{array}$ & 2 & 0 & 0 & 0 \\
\hline 4 & Moli Fan (6) & 3060 & . & . & $4 / 94$ & . & 2 & 0 & o & 0 \\
\hline 5 & $\begin{array}{l}\text { Mohammad Ali } \\
\text { Sahraian (7) }\end{array}$ & 149 & $37.55 \pm 11.57$ & 6.22 & $7.95 \pm 4.71$ & $\begin{array}{c}\text { Fever, Dyspnea, } \\
\text { myyalgi, } \\
\text { Gastrointestinal } \\
\text { complications, } \\
\text { fatigue, and vertigo }\end{array}$ & 5 & 3 & 0 & 0 \\
\hline
\end{tabular}

$\begin{array}{lll}\text { Study } & \text { ES (95\% CI) Weight }\end{array}$

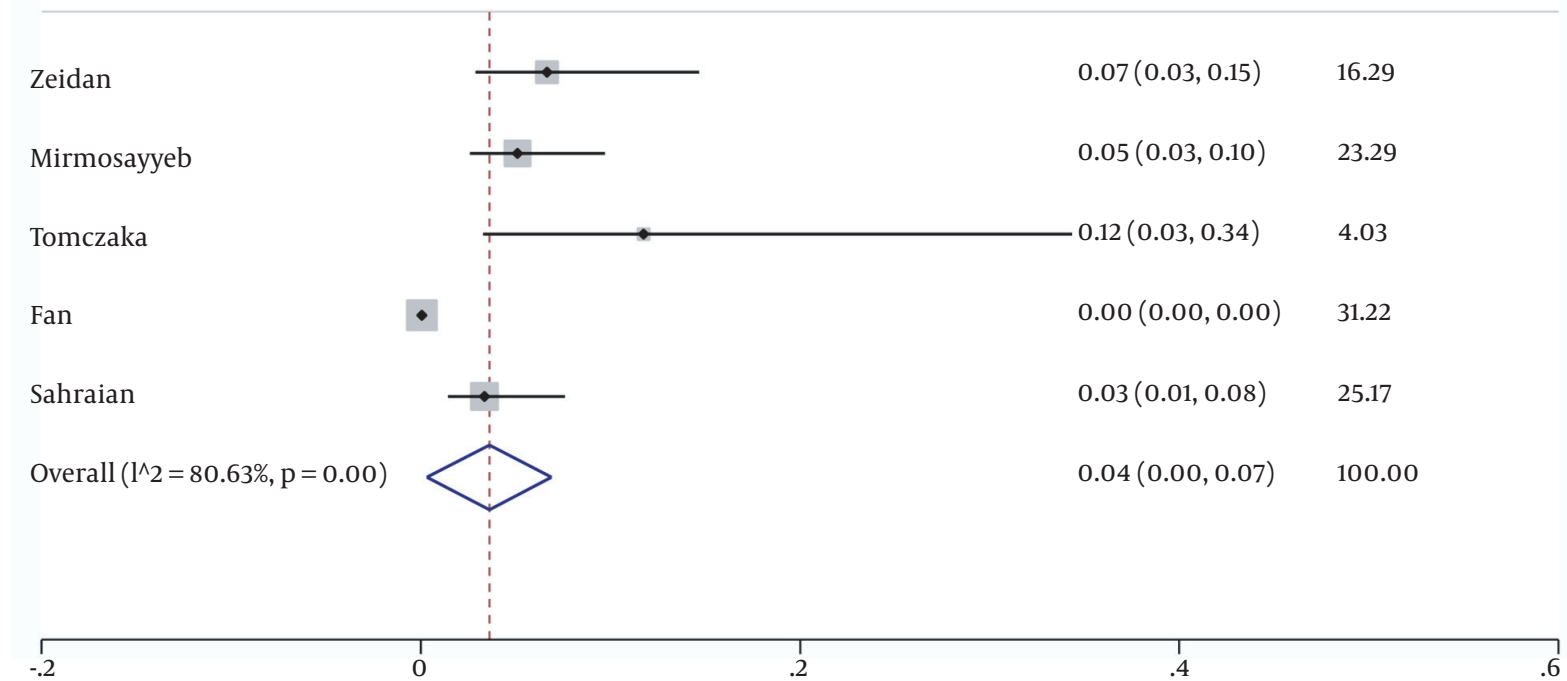

Funding/Support: The authors declared that they had no funding/support.

Informed Consent: All authors consent for publication.

\section{References}

1. Barzegar M, Mirmosayyeb O, Ghajarzadeh M, Nehzat N, Vaheb S, Shaygannejad V, et al. Characteristics of COVID-19 disease in multiple sclerosis patients. Mult Scler Relat Disord. 2020;45:102276. doi: 10.1016/j.msard.2020.102276. [PubMed: 32652473]. [PubMed Central: PMC7278648].

2. Ghajarzadeh M, Bonavita S. Are patients with multiple sclerosis (MS) at higher risk of COVID-19 infection? Neurol Sci. 2020;41(9):2315-6. doi: 10.1007/s10072-020-04570-8. [PubMed: 32638135]. [PubMed Central: PMC7340752].

3. Mirmosayyeb O, Vaheb S, Barzegar M, Shaygannejad V, Bonavita $S$, Ghajarzadeh M. Screening neuromyelitis optica patients for COVID-19 infection. Autoimmun Rev. 2020;19(11):102669. doi 10.1016/j.autrev.2020.102669. [PubMed: 32942032]. [PubMed Central: PMC7489250].

4. Zeidan S, Maillart E, Louapre C, Roux T, Lubetzki C, Papeix C. COVID-19 infection in NMO/SD patients: a French survey. J Neurol. 2021;268(4):1188-90. doi: 10.1007/s00415-020-10112-1. [PubMed: 32920657]. [PubMed Central: PMC7486806].

5. Tomczak A, Han MH. The impact of COVID-19 on patients with neuromyelitis optica spectrum disorder; a pilot study. Mult Scler Relat 
Disord. 2020;45:102347. doi: 10.1016/j.msard.2020.102347. [PubMed: 32645636].

6. Fan M, Qiu W, Bu B, Xu Y, Yang H, Huang D, et al. Risk of COVID-19 infection in MS and neuromyelitis optica spectrum disorders. Neurol Neuroimmunol Neuroinflamm. 2020;7(5). doi: 10.1212/NXI.0000000000000787. [PubMed: 32503092]. [PubMed Central: PMC7286663]

7. Sahraian MA, Azimi A, Navardi S, Rezaeimanesh N, Naser Moghadasi
A. Evaluation of COVID-19 infection in patients with Neuromyelitis optica spectrum disorder (NMOSD): A report from Iran. Mult Scler Relat Disord. 2020;44:102245. doi: 10.1016/j.msard.2020.102245. [PubMed: 32512287]. [PubMed Central: PMC7832017].

8. Signorelli C, Scognamiglio T, Odone A. COVID-19 in Italy: impact of containment measures and prevalence estimates of infection in the general population. Acta Bio Medica: Atenei Parmensis. 2020;91(Suppl 3):175-9. 